\title{
$P R K C H$ gene polymorphism is associated with the risk of severe gastric atrophy
}

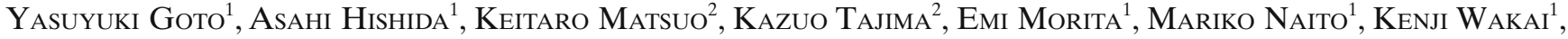 \\ and Nobuyuki Hamajima ${ }^{1}$ \\ ${ }^{1}$ Department of Preventive Medicine / Biostatistics and Medical Decision Making, Nagoya University Graduate School of Medicine, \\ 65 Tsurumai-cho, Showa-ku, Nagoya 466-8550, Japan \\ ${ }^{2}$ Division of Epidemiology and Prevention, Aichi Cancer Center Research Institute, Nagoya, Japan
}

\begin{abstract}
Background. Individuals infected with Helicobacter pylori do not necessarily develop gastric atrophy (GA) and gastric cancer (GC). Several factors, including genetic polymorphism, can regulate the development of GA and GC. A $G / A$ single nucleotide polymorphism (rs3783799) of the PRKCH gene, which encodes the $\eta$ isozyme of protein kinase $\mathrm{C}$ (PKC $\eta$ ), has been reported to be a tag single nucleotide polymorphism (SNP) of the PRKCH gene linked to a functional $1425 G / A$ SNP in exon 9 (rs2230500). To elucidate its applicability in the development of GA and GC, this study aimed to investigate the associations of the $P R K C H$ polymorphism with the risks of GA and GC.

Methods. The subjects consisted of 583 patients (cases) from first-visit outpatients at Aichi Cancer Center Hospital, aged 27 to 80 years, who were diagnosed as having GC from 2001 to 2005 , and 1742 controls, frequency-matched for age and sex. Anti-H. pylori IgG antibodies and pepsinogens (PGs) in serum were measured for 1638 controls.

Results. Of the 1638 controls, $57.3 \%$ were seropositive and 33.0\% had GA (PG1 $\leq 70 \mathrm{ng} / \mathrm{dl}$ and PG1/PG2 $\leq 3$ ). When compared to the seronegative controls without $G A$, the $A A$ genotype was significantly associated with severe GA (PG1 $\leq 30$ ng/dl and PG1/PG2 $\leq$ 2); odds ratio (OR), 2.37 (95\% confidence interval, $1.11-5.05)$ relative to the $G G$ genotype. The genotype was not associated with the risk of GC. Conclusion. This was the first study to examine the associations of the PRKCH polymorphism with GA and GC, and suggested that the $A A$ genotype, relative to the $G / G$ genotype, may be a higher risk genotype for severe GA.
\end{abstract}

Key words $\mathrm{PRKCH} \cdot$ Polymorphism - Helicobacter pylori Severe gastric atrophy

Offprint requests to: Y. Goto

Received: July 23, 2009 / Accepted: December 25, 2009

\section{Introduction}

Helicobacter pylori is an established risk factor for both intestinal-type and diffuse-type gastric cancer (GC), especially for the former [1,2]. The development of intestinal GC begins with gastric atrophy (GA) induced by $H$. pylori. According to the cascade of events described by Correa et al. [3], H. pylori infection causes chronic inflammation, which then progresses through the GA-metaplasia-dysplasia-carcinoma sequence [3, 4]. However, this progression is affected by many factors, including salty food consumption, low fruit intake, the immune reaction of the host to the infection $[4,5]$, and genetic traits measurable by genotypes. To date, we have already reported several polymorphisms possibly associated with $H$. pylori seropositivity, GA, and GC [6-9].

Protein kinase $\mathrm{C}(\mathrm{PKC})$ ) is involved in oxidative stress, resulting in the induction of inducible nitric oxide synthase (iNOS) and nitric oxide (NO) production. Indeed, blood samples from patients with severe rheumatoid arthritis (RA) showed a positive relationship between the activity of the PKC $\eta$ and iNOS enzymes [10]. This finding also suggests that $\mathrm{PKC \eta}$ could mediate iNOS after $H$. pylori infection, because iNOS expression in the gastric mucosa is higher in $\mathrm{H}$. pylori-positive individuals than in $H$. pylori negative individuals [11, 12]. iNOS can produce large amounts of NO, which reacts with superoxide produced by $H$. pylori infection [13] to form peroxynitrite, which has strong oxidizing properties, leading to the development of GA. In addition, PKC $\eta$ can mediate cell proliferation through the ERK/ Elk-1 [14] and Akt pathways [15].

The $P R K C H$ gene, which is located on chromosome 14q22-23, encodes PKC $\eta$. The association of multiple PRKCH gene polymorphisms with RA [16] and with cerebral infarction $[17,18]$ has been reported. However, there are no studies regarding the association between $P R K C H$ gene polymorphisms and GA and GC. 
It was reported that two single nucleotide polymorphisms (SNPs; rs3783799 and rs2203500) in the PRKCH gene, which were in complete linkage disequilibrium (LD), were associated with cerebral infarction; the former was a tag SNP of the PRKCH gene and the latter was confirmed to be functional by a series of biological assays in vitro $[17,18]$. To elucidate its applicability in the development of GA and GC, we investigated the association between the $\mathrm{PRKCH}$ gene polymorphism (rs3783799) and the H. pylori-induced inflammation of gastric mucosa leading to GA and GC.

\section{Subjects and methods}

\section{Study subjects}

The study subjects were derived from the Hospitalbased Epidemiological Research Program at Aichi Cancer Center (HERPACC) that was launched in 1988. Details of the study design and data collection procedures were described in previous reports [19-21]. Briefly, all first-visit outpatients at Aichi Cancer Center Hospital $(\mathrm{ACCH})$ were asked to complete a self-administered questionnaire on their lifestyle, past history, and family history, including items on demographic characteristics, medical history, smoking and drinking habits, regular physical exercise, and dietary habits, before the development of current symptoms, as well as menstrual and reproductive history for women. The questionnaire was checked for unanswered items and contradictory responses, by trained interviewers. In the present study, there were 583 patients, aged 27 to 80 years, who were diagnosed with GC from 2001 to 2005 (cases), and 1742 cancer-free participants (controls) who were frequencymatched to the cases in terms of age and sex. Informed consent was obtained from all the subjects and the study protocol was approved by the Ethics Committees of Aichi Cancer Center and Nagoya University Graduate School of Medicine.

\section{Tests for $\mathrm{H}$. pylori antibody and pepsinogens}

Anti-H. pylori $\mathrm{IgG}$ antibody in serum was measured with an enzyme immunoassay (EIA) kit (E plate "Eiken" H. pylori Antibody; Eiken, Tokyo, Japan). A value of $10.0 \mathrm{U} / \mathrm{ml}$ or greater was regarded as being $H$. pylori infection-positive. Concentrations of serum pepsinogens 1 and 2 (PG1 and PG2) were measured by radioimmunoassay, using a commercially available kit (Dinabot, Tokyo, Japan). PG1values of $70 \mathrm{ng} / \mathrm{ml}$ or less and a PG1/PG2 ratio of 3 or less were regarded as indicating the presence of GA. Mild GA was defined as values excluding severe GA (PG1 $\leq 30 \mathrm{ng} / \mathrm{ml}$ and PG1/ PG2 $\leq 2)$.

\section{Genotyping}

DNA was extracted from whole blood using a Qiagen mini kit (Qiagen Group, Tokyo, Japan). A tag SNP, SNP_15 in PRKCH (rs3783799, IMS_JST140193), was genotyped by a TaqMan assay using an ABI PRISM 7300 sequence detection system (Applied Biosystems, Foster City, CA, USA), in accordance with the manufacturer's instructions. Thermal cycling conditions for polymerase chain reaction (PCR) were, first, denaturing at $95^{\circ} \mathrm{C}$ for $10 \mathrm{~min}$, followed by 50 cycles of $92^{\circ} \mathrm{C}$ for $15 \mathrm{~s}$ and $58^{\circ} \mathrm{C}$ for $1 \mathrm{~min}$.

\section{Statistical analysis}

Odds ratios (ORs) adjusted for sex and age with 95\% confidence intervals (CIs) were calculated using unconditional logistic regression analysis. Hardy-Weinberg equilibrium was tested for the $P R K C H$ polymorphism in controls by a $\chi^{2}$ test with $1 \mathrm{df}$. These calculations were performed with the software program STATA Version 9 (STATA, College Station, TX, USA).

\section{Results}

The characteristics of the study subjects are summarized in Table 1. Male subjects accounted for the majority in both the controls and cases, at $73.8 \%$ and $73.6 \%$, respectively. H. pylori antibody and PGs were not measured in the cases or in 104 controls whose serum samples were not sufficient for the measurements. The frequencies of $H$. pylori seropositivity and GA among the remaining 1638 controls were $939(57.3 \%)$ and 541 $(33.0 \%)$, respectively. DNA was not successfully extracted in 4 controls and 4 cases and therefore these patients could not be genotyped. The genotype frequency in the 1738 controls was in Hardy-Weinberg equilibrium $\left(\chi^{2}=0.74 ; P=0.39\right)$.

There were 45 seronegatives with GA, who were regarded as having been infected with $H$. pylori in the past; 17 were classified as having mild GA, and 28 as having severe GA. According to the Correa cascade [3], the controls were divided into four groups: the seronegative controls without GA, and the seropositive ones without GA, with mild GA, and with severe GA. Compared to the seronegative controls without GA, the OR of the $A A$ genotype relative to the $G G$ genotype was 2.37 (95\% CI, 1.11-5.05) for severe GA (Table 2). However, the OR was not significant in the comparisons between the seropositives without GA and those with GA (both mild and severe), and between mild GA and severe GA (data not shown).

The comparisons between 1738 controls, including subjects without the results of laboratory tests, and 579 
Table 1. Characteristics of the study subjects

\begin{tabular}{|c|c|c|c|c|}
\hline \multirow[b]{2}{*}{ Characteristics } & \multicolumn{2}{|c|}{ Controls } & \multicolumn{2}{|c|}{ Cases } \\
\hline & Number & $\%$ & Number & $\%$ \\
\hline \multicolumn{5}{|l|}{ Sex } \\
\hline Male & 1286 & 73.8 & 429 & 73.6 \\
\hline Female & 456 & 26.2 & 154 & 26.4 \\
\hline Age in years $($ mean $\pm \mathrm{SD})$ & \multicolumn{2}{|c|}{$58.5 \pm 10.6$} & \multicolumn{2}{|c|}{$58.8 \pm 10.5$} \\
\hline \multicolumn{5}{|c|}{ Anti-Helicobacter pylori IgG antibody } \\
\hline Positive & 939 & 57.3 & - & - \\
\hline Negative & 699 & 42.7 & - & - \\
\hline No serum & 104 & - & - & - \\
\hline \multicolumn{5}{|c|}{ Gastric atrophy measured with pepsinogens } \\
\hline Positive & 541 & 33.0 & - & - \\
\hline Negative & 1097 & 67.0 & - & - \\
\hline No serum & 104 & - & - & - \\
\hline \multicolumn{5}{|l|}{$P R K C H$} \\
\hline$G / G$ & 1068 & 61.5 & 343 & 59.2 \\
\hline$G / A$ & 581 & 33.4 & 213 & 36.8 \\
\hline$A / A$ & 89 & 5.1 & 23 & 4.0 \\
\hline Not genotyped & 4 & - & 4 & - \\
\hline
\end{tabular}

Table 2. Sex- and age-adjusted odds ratios (ORs) and $95 \%$ confidence intervals (95\% CIs) of $P R K C H$ genotypes for sensitivity to H. pylori infection and gastric atrophy (GA) by the degree of severity, compared with seronegative non-GA controls ${ }^{\mathrm{a}}$

\begin{tabular}{|c|c|c|c|c|c|c|c|c|c|c|}
\hline \multirow[b]{2}{*}{ Genotype } & \multirow{2}{*}{$\begin{array}{c}\begin{array}{c}\text { Seronegative non-GA } \\
(n=651)\end{array} \\
n(\%)\end{array}$} & \multicolumn{3}{|c|}{$\begin{array}{c}\text { Seropositve non-GA }{ }^{\mathrm{b}} \\
(n=443)\end{array}$} & \multicolumn{3}{|c|}{$\begin{array}{l}\text { Mild GA }{ }^{c} \\
(n=344)\end{array}$} & \multicolumn{3}{|c|}{$\begin{array}{l}\text { Severe GA }{ }^{\mathrm{d}} \\
\quad(n=196)\end{array}$} \\
\hline & & $n(\%)$ & OR & $95 \%$ CI & $n(\%)$ & OR & $95 \% \mathrm{CI}$ & $n(\%)$ & OR & $95 \%$ CI \\
\hline$G / G$ & 4 & $7(60.3)$ & 1 & e & (63.1) & 1 & & 11 & 1 & $\mathrm{Re}$ \\
\hline$G / A$ & $221(34.0)$ & $156(35.2)$ & 1.03 & $0.79-1.34$ & $105(30.5)$ & 0.90 & $0.67-1.20$ & $68(34.7)$ & 0.99 & $0.68-1.43$ \\
\hline$A / A$ & $29(4.4)$ & $20(4.5)$ & 1.16 & $0.63-2.14$ & $22(6.4)$ & 1.53 & $0.85-2.77$ & $14(7.1)$ & 2.37 & $1.11-5.05$ \\
\hline$G / A+A / A$ & $250(38.4)$ & $176(39.7)$ & 1.04 & $0.81-1.34$ & $127(36.9)$ & 0.97 & $0.73-1.28$ & $82(41.8)$ & 1.11 & $0.78-1.58$ \\
\hline
\end{tabular}

PG, pepsinogen

${ }^{\text {a }}$ Seronegative controls without GA (PG1 $\leq 70 \mathrm{ng} / \mathrm{dl}$ and PG 1/2 $\leq 3$ )

${ }^{\mathrm{b}}$ Seropositive controls without GA

${ }^{\mathrm{c}}$ Controls with GA except those with PG1 $\leq 30 \mathrm{ng} / \mathrm{dl}$ and PG1/2 $\leq 2$

${ }^{\mathrm{d}}$ Controls with PG1 $\leq 30 \mathrm{ng} / \mathrm{dl}$ and PG1/2 $\leq 2$

Table 3. Sex- and age-adjusted odds ratios (ORs) and $95 \%$ confidence intervals (95\% CIs) for gastric cancer of $\mathrm{PRKCH}$ genotypes

\begin{tabular}{lrrcc}
\hline Polymorphism & Controls & Cases & OR & $95 \%$ CI \\
\hline$G / G$ & 1068 & 343 & 1 & Reference \\
$G / A$ & 581 & 213 & 1.14 & $0.94-1.39$ \\
$A / A$ & 89 & 23 & 0.81 & $0.50-1.29$ \\
$G / A+A / A$ & 670 & 236 & 1.10 & $0.90-1.33$ \\
\hline
\end{tabular}

cases showed that the PRKCH polymorphism was not associated with the risk for GC (Table 3).

\section{Discussion}

The present study found that the $\mathrm{PRKCH}$ minor homozygous genotype was significantly associated with severe
GA (OR, 2.37) in the comparison between the seronegative controls without GA and the controls with severe GA. According to the cascade described by Correa et al. [3], three steps are included in the significant association between $H$. pylori infection and GA: (i) persistent H. pylori infection, (ii) GA development, and (iii) progression to severe GA. Each step was examined in the present study, but a significant OR was not detected for any steps, partly due to the limited statistical power of the study. Therefore, it is possible that the genotype could affect all steps to severe GA to a certain extent. Otherwise, considering that the OR for severe GA was significant and that the gradually elevated ORs for $H$. pylori seropositivity without GA and mild GA were assumed to be random phenomena, we could not deny the possibility that the genotype may have influenced the last step of the progression to severe GA. Actually, this progression could be possibly explained from a 
biological point of view. The relationship between $\mathrm{PKC \eta}$, encoded by $P R K C H$, and iNOS has been reported [10]. Furthermore, iNOS has been shown to be expressed in the gastric mucosa of patients with GA [11, 12], and it can produce large amounts of NO [22]. Reactive nitrogen oxide species formed from the reaction of $\mathrm{NO}$ either with oxygen or superoxide can cause tissue damage, leading to the development of GA [13, 23, 24]. Accordingly, one plausible biological mechanism operating in the present study was that subjects with the $A A$ genotype had higher $\mathrm{PKC} \eta$ activity and produced large amounts of NO through iNOS, which could be enhanced through $H$. pylori infection [11], resulting in facilitating the progression from mild GA to severe GA. In fact, a $1425 G / A$ SNP (leading to V371I) within an ATP-binding

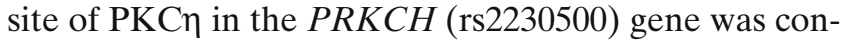
firmed to be functional by a series of biological assays in vitro [17]. PKCn-374I had 1.6 times higher activity than PKCn-374V. This SNP was in complete LD with the rs3783799 we adopted in the present study $[17,18]$.

Multiple SNPs have been located in the PRKCH gene. Among them, rs3783799 and rs2230500 have been reported to be associated with cerebral infarction [17, 18]. Other SNPs in the PRKCH gene, found in intron 2 , 5 , or 9, were reported to be associated with RA [16]. We used rs3783799, not rs2230500, in the present study, because this genetic polymorphism is a tag SNP of the $P R K C H$ gene and was linked to a functional $1425 G / A$ in exon 9 (rs2230500) $[17,18]$. We could not genotype rs2230500 with TaqMan. Serizawa et al. [18] reported that they genotyped rs2230500 using the Mass ARRAY system, instead of TaqMan. Moreover, considering that the rs3783799 SNP is completely linked to rs2230500 $[17,18]$, we thought it redundant to evaluate the associations of rs2230500 with GA and GC. Regarding rs3783799, there was no remarkable difference in the minor allele frequency between the controls in the present study and the HapMap database for Japanese; the frequency in the former was 0.218 and in the latter was 0.239 . The minor allelic frequencies in other populations were reported in the HapMap database as 0.178 in Han Chinese in Beijing, 0.008 in CEPH samples (Utah residents with ancestry from northern and western Europe), and 0.000 in Yoruba from Ibadan, Nigeria. These data suggest that the rs3783799 SNP is likely to be limited to Asian populations.

We could not find any association of the $P R K C H$ gene polymorphism with the development of GC (Table 3 ). This result might reflect the fact that the effect of $\mathrm{PKC} \eta$ on proliferation depends on the cell type. PKC $\eta$ can enhance the proliferation of glioblastoma cells [15] and epithelial breast adenocarcinoma [25]. However, other cell types, such as keratinocytes, inhibit the effect of PKC $\eta$ on cell-cycle progression [26]. PKC $\eta$ probably has no effect on the proliferation of GC cells.
In the present study, there were 45 seronegative controls with GA, of whom 17 had mild GA. It is well known that $H$. pylori is spontaneously eliminated through intestinal metaplasia replacement, resulting in the loss of $H$. pylori serological markers [27, 28]. Hence, we supposed that the above 17 controls had lost their seropositivity not due to the severity of GA but probably due to $H$. pylori eradication therapy, because the spontaneous regression or clearance of $H$. pylori is rare under normal circumstances [29-31], and extensive mucosal atrophy and intestinal metaplasia were found to be irreversible even after $H$. pylori eradication [32]. Therefore, we regarded the above 17 seronegative controls as having mild GA, not severe GA, for the purpose of assessing the effect of this genetic polymorphism on the development of mild GA.

There was a limitation in this study. For the cases, we did not have information on the status of $H$. pylori infection, including the titer of $H$. pylori antibody and levels of PGs. Because resources were limited for carrying out serological studies, the status of $H$. pylori infection and levels of PGs were not examined for the GC cases. We have already planned other studies with a higher priority than this study.

In conclusion, this was the first study to show that a $P R K C H$ gene polymorphism could affect the development of severe GA, and it may provide a clue to finding a new mechanism related to the development of GA and GC. Replication studies in other independent populations are required to confirm these results.

Acknowledgments This work was supported in part by a Grant-in-Aid for Scientific Research on Special Priority Areas of Cancer from the Japanese Ministry of Education, Culture, Sports, Science and Technology. The authors are very grateful to Ms. Yoko Mitsuda and Ms. Keiko Shibata for their technical assistance.

\section{References}

1. Ohata H, Kitauchi S, Yoshimura N, Mugitani K, Iwane M, Nakamura $\mathrm{H}$, et al. Progression of chronic atrophic gastritis associated with Helicobacter pylori infection increases risk of gastric cancer. Int J Cancer 2004;109:138-43.

2. Caputo S, Mosca F, Persi A, Ettaro G, Scaringi S, Russo G, et al. Helicobacter pylori and gastric cancer. The incidence of infection in personal experience. Minerva Chir 2002;57:649-55.

3. Correa P, Haenszel W, Cuello C, Tannenbaum S, Archer M. A model for gastric cancer epidemiology. Lancet 1975;II:58-9.

4. Correa P, Piazuelo MB. Natural history of Helicobacter pylori infection. Dig Liver Dis 2008;40:490-6.

5. Palli D. Epidemiology of gastric cancer: an evaluation of available evidence. J Gastroenterol 2000;35:84-9.

6. Goto Y, Ando T, Yamamoto K, Tamakoshi A, El-Omar E, Goto $\mathrm{H}$, et al. Association between serum pepsinogens and polymorphism of PTPN11 encoding SHP-2 among Helicobacter pylori seropositive Japanese. Int J Cancer 2006;118:203-8. 
7. Goto Y, Ando T, Naito M, Goto H, Hamajima N. Inducible nitric oxide synthase polymorphism is associated with the increased risk of differentiated gastric cancer in a Japanese population. World J Gastroenterol 2006;12:6361-5.

8. Goto Y, Ando T, Nishio K, Kawai S, Ishida Y, Naito M, et al. Grb2associated binder 1 polymorphism was associated with the risk of Helicobacter pylori infection and gastric atrophy. Int J Med Sci 2006;4:-6.

9. Hishida A, Matsuo K, Goto Y, Mitsuda Y, Hiraki A, Naito M, et al. Toll-like receptor $4+3725 \mathrm{G} / \mathrm{C}$ polymorphism, Helicobacter pylori seropositivity, and the risk of gastric atrophy and gastric cancer in Japanese. Helicobacter 2009;14:47-53.

10. Pham TN, Rahman P, Tobin YM, Khraishi MM, Hamilton SF, Alderdice $\mathrm{C}$, et al. Elevated serum nitric oxide levels in patients with inflammatory arthritis associated with co-expression of inducible nitric oxide synthase and protein kinase C-eta in peripheral blood monocyte-derived macrophages. J Rheumatol 2003; 30:2529-34.

11. Goto T, Haruma K, Kitadai Y, Ito M, Yoshihara M, Sumii K, et al. Enhanced expression of inducible nitric oxide synthase and nitrotyrosine in gastric mucosa of gastric cancer patients. Clin Cancer Res 1999;5:1411-5.

12. Pignatelli B, Bancel B, Estève J, Malaveille C, Calmels S, Correa $\mathrm{P}$, et al. Inducible nitric oxide synthase, anti-oxidant enzymes and Helicobacter pylori infection in gastritis and gastric precancerous lesions in humans. Eur J Cancer Prev 1998;7:439-47.

13. Bagchi D, Bhattacharya G, Stohs SJ. Production of reactive oxygen species by gastric cells in association with Helicobacter pylori. Free Radic Res 1996;24:439-50.

14. Uht RM, Amos S, Martin PM, Riggan AE, Hussaini IM. The protein kinase $\mathrm{C}$-eta isoform induces proliferation in glioblastoma cell lines through an ERK/Elk-1 pathway. Oncogene 2007;26: 2885-93.

15. Aeder SE, Martin PM, Soh JW, Hussaini IM. PKC-eta mediates glioblastoma cell proliferation through the Akt and mTOR signaling pathways. Oncogene 2004;23:9062-9.

16. Takata Y, Hamada D, Miyatake K, Nakano S, Shinomiya F, Scafe $\mathrm{CR}$, et al. Genetic association between the $P R K C H$ gene encoding protein kinase Ceta isozyme and rheumatoid arthritis in the Japanese population. Arthritis Rheum 2007;56:30-42.

17. Kubo M, Hata J, Ninomiya T, Matsuda K, Yonemoto K, Nakano $\mathrm{T}$, et al. A nonsynonymous SNP in PRKCH (protein kinase C eta) increases the risk of cerebral infarction. Nat Genet 2007;39: 212-7.

18. Serizawa M, Nabika T, Ochiai Y, Takahashi K, Yamaguchi S, Makaya $\mathrm{M}$, et al. Association between $P R K C H$ gene polymor- phisms and subcortical silent brain infarction. Atherosclerosis 2008;199:340-45.

19. Inoue M, Tajima K, Hirose K, Kuroishi T, Gao CM, Kitoh T. Lifestyle and subsite of gastric cancer-joint effect of smoking and drinking habits. Int J Cancer 1994;56:494-9.

20. Takezaki T, Hirose K, Inoue M, Hamajima N, Yatabe Y, Mitsudomi $\mathrm{T}$, et al. Dietary factors and lung cancer risk in Japanese: with special reference to fish consumption and adenocarcinomas. Br J Cancer 2001;84:1199-206.

21. Yang CX, Takezaki T, Hirose K, Inoue M, Huang XE, Tajima K. Fish consumption and colorectal cancer: a case-reference study in Japan. Eur J Cancer Prev 2003;12:109-15.

22. Nathan C. Inducible nitric oxide synthase: what difference does it make? J Clin Invest 1997;100:2417-23.

23. Wink DA, Mitchell JB. Chemical biology of nitric oxide: insights into regulatory, cytotoxic and cytoprotective mechanisms of nitric oxide. Free Rad Biol Med 1998;25:434-56.

24. Beckman JS, Koppenol WH. Nitric oxide, superoxide, and peroxynitrite: the good, the bad, and ugly. Am J Physiol 1996;271: C1424-37.

25. Fima E, Shtutman M, Libros P, Missel A, Shahaf G, Kahana G, et al. PKCeta enhances cell cycle progression, the expression of G1 cyclins and p21 in MCF-7 cells. Oncogene 2001;20:6794-804.

26. Kashiwagi M, Ohba M, Watanabe H, Ishino K, Kasahara K, Sanai $\mathrm{Y}$, et al. PKCeta associates with cyclin E/cdk2/p21 complex, phosphorylates p21 and inhibits cdk2 kinase in keratinocytes. Oncogene 2000;19:6334-41.

27. Asaka M, Sugiyama T, Nobuta A, Kato M, Takeda H, Graham DY. Atrophic gastritis and metaplasia in Japan: results of a large multicenter study. Helicobacter 2000;6:294-9.

28. Lambert JR, Lin SK, Aranda-Michel J. Helicobacter pylori. Scand J Gastroenterol 1995;208:33-46.

29. Freeman HJ. Disappearance of Helicobacter without antibiotics in 12 patients with gastritis. Can J Gastroenterol 1997;11:167-72.

30. Bair MJ, Wu MS, Chang WH, Shih SC, Wang TE, Chen CJ, et al. Spontaneous clearance of Helicobacter pylori colonization in patients with partial gastrectomy: correlates with operative procedures and duration after operation. J Formos Med Assoc 2009;108:13-9.

31. Xia HH, Talley NJ. Natural acquisition and spontaneous elimination of Helicobacter pylori infection: clinical implications. Am J Gastroenterol 1997;92:1780-7.

32. Iijima K, Koike T, Sekine H, Abe Y, Asanuma K, Ara N, et al. Sustained epithelial proliferation in a functionally irreversible fundic mucosa after Helicobacter pylori eradication. J Gastroenterol 2009;44:47-55. 